\begin{tabular}{|c|c|c|}
\hline 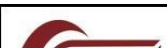 & RACIC 6 (1) (2021) & 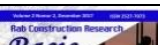 \\
\hline U & JURNAL RAB CONTRUCTION RESEARCH & \\
\hline $\begin{array}{l}\text { UNIVERSITAS } \\
\text { ABDURRAB }\end{array}$ & http://jurnal.univrab.ac.id/index.php/racic & 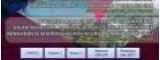 \\
\hline
\end{tabular}

\title{
ANALISIS PELAT LANTAI MENGGUNAKAN METODE HIRZFELD
}

\author{
Novia Siti Rohana ${ }^{1}$, Mahfuz Hudori ${ }^{2}$ \\ Program Sarjana Teknik Sipil, Fakultas Teknik Sipil dan Perencanaan, Universitas Internasional Batam \\ J1. Gajah Mada, Sei Ladi, Baloi - Kota Batam \\ Telp (0778) 7437111 \\ Alamat e-mail ${ }^{1} 1711046 . n o v i a @ u i b . e d u,{ }^{2}$ mahfuz@uib.ac.id
}

\begin{abstract}
Info Artikel Abstrak

Sejarah Artikel:

Diterima: Oktober 2020

Disetujui: Juni 2021

Dipublikasikan: 30 Juni 2021

Pada saat ini pembangunan rumah mewah di Kota Batam berkembang sangat pesat. Hal tersebut membuktikan bahwa pelaku konstruksi di Kota Batam berhasil merencanakan bangunan. Penelitian ini dilakukan di proyek pembangunan rumah mewah Bukit Permata Baloi Kota Batam. Pada penelitian ini akan dilaksanakan analisis pelat lantai menggunakan Metode Hirzfeld. Hal ini dilakukan guna untuk mengetahui besar koefisien defleksi dan momen lentur yang terjadi pada dua pelat dengan dimensi berbeda yang memiliki empat kasus berbeda pula. Setelah dilakukan analisis maka, diperoleh hasil yaitu semakin besar dimensi pelat maka didapatkan koefisien defleksi dan momen lentur yang besar pula
\end{abstract}

Keywords: metode hirzfeld momen lentur, pelat lantai, rumah mewah
Kata Kunci: Metode Hirzfeld, Momen Lentur, Pelat Lantai, Rumah Mewah

\section{Abstract}

Currently construction of the royal house is growing very fast at Batam City. The matter proves that are people's construction is successfully for planning the building at Batam City. This research was conducted at the Bukit Permata Baloi royal house construction project, Batam City. In this study, the Floor Slab Analysis will be carried out using with Hirffeld Method. This is done for knowing the main deflection coefficient and flexible moment of the floor slabs with different dimensions have different four cases. After analyzed then, obtain results that are the higher dimension of the floor slab then obtain the higher deflection coefficient and flexible moment also.

Keywords: Flexible Moment, Floor Slab, Hirzfeld Method, Royal House

Jl. Gajah Mada Sei Ladi, Baloi - Kota Batam

E-mail: 1711046.novia@uib.edu 


\section{PENDAHULUAN}

Pada era ini kemajuan perencanaan konstruksi di Kota Batam sangat cepat, khususnya di bidang konstruksi bangunan mewah. Hal tersebut menjadi bukti bahwa manusia yang berperan sebagai pelaku konstruksi di Kota Batam berhasil merencanakan bangunan yang aman, nyaman, dan ekonomis. Konstruksi bangunan mewah adalah salah satu konstruksi yang terdiri dari elemen-elemen seperti pondasi, sloof, balok, kolom, pelat lantai, dinding dan lain-lain yang telah direncanakan dengan tujuan agar kondisi optimum konstruksi dapat terpenuhi dengan baik.

Seperti yang telah disebutkan di atas, konstruksi terdiri dari elemen-elemen dan salah satunya adalah pelat lantai. Pelat lantai adalah suatu pembatas antara tingkat bawah dan tingkat atasnya. Pelat lantai juga dapat disebut sebagai beton bertulang yang tersusun dari tulangan baja yang disusun secara memanjang (long) dan melintang (cross) kemudian diikat dengan kawat besi yang telah direncanakan sesuai dengan beban yang akan didukung. Jenis tumpuan pada pelat lantai dibagi menjadi beberapa misalnya tumpuan bebas, tumpuan jepit dan tumpuan sederhana.

Ada beberapa macam metode yang digunakan dalam analisa pelat lantai. Analisa tersebut biasanya digunakan untuk menghitung besaran yang terjadi pada pelat lantai yang diakibatkan oleh gaya momen, defleksi, reaksi perletakan dan lain-lain. Besaran-besaran tersebut harus diperhatikan karena sangat berpengaruh pada tahap perencanaan. Oleh karena itu, perlu dilakukan analisa pelat lantai secara detail agar struktur tersebut dapat mendukung gayagaya yang bekerja.

\section{TINJAUAN PUSTAKA}

\section{Beton}

Penulisan Beton yaitu komposit dari beberapa bahan. Material utama beton yaitu semen portland, pasir sebagai agregat halus, kerikil sebagau agregat kasar, air dan zat adiktif lainnya. Material-material tersebut dicampur menjadi satu dengan perbandingan tertentu, sehingga membentuk seperti batu. Beton merupakan salah satu bahan konstruksi yang cukup kompleks. Pada dasarnya beton dapat diproduksi oleh siapapun sampai orang yang tidak memiliki pengetahuan tentang teknologi bahan beton. Akan tetapi, hal tersebut membuat salah pengertian. Dari kesederhanaan tersebut membuat hasil dari beton tersebut jelek sebagai material bangunan. Diantara berbagai cara yang digunakan untuk memperbaiki sifat-sifat bahan beton yaitu dengan cara melakukan transformasi agregat campuran yang digunakan pada beton [1].

Beton merupakan salah satu material yang lemah menahan gaya tarik dan kuat dalam menahan tekanan. Nilai kuat tarik beton bekisar antar 9\% - 15\% [4]. Oleh karena itu, beton harus diperkuat dengan cara menambahkan baja tulangan guna untuk menahan gaya tarik akibat 
beban yang didukung oleh beton tersebut. Ada beberapa hal yang dapat mempengaruhi kekuatan beton seperti material campuran beton, persiapan, percobaan hingga perawatan (curing) beton. Faktor tersebut disebabkan oleh komponen-komponen yang sifatnya alami dan tidak bisa dihindari. Akan tetapi, dengan memahami karakteristik material penyusun tersebut maka, dapat diketahui juga kebutuhan setiap material penyusun dan kekuatan (strength) yang hendak dicapai.

\section{Klasifikasi Beton}

1. Berdasarkan Kelas dan Mutu Beton

Berdasarkan mutu dan kelasnya, beton diklasifikasikan sebagai berikut:

a. Beton kelas I

Beton kelas I merupakan beton yang biasanya digunakan untuk pekerjaan non struktural. Pelaksanaan belon kelas I tidak membutuhkan keahlian khusus. Pengawasan mutu beton kelas I dibatasi hanya sampai pada inspeksi ringan terhadap kualitas material sedangkan untuk kuat tekan tidak ditentukan pemeriksaannya.

b. Beton kelas II

Beton kelas dua merupakan beton yang digunakan pada pekerjaan umum. Pada pelaksanaan belon kelas dua membutuhkan keahlian tinggi dan dikerjakan berdasarkan pengawasan pimpinan ahli. Mutu beton kelas dua dibedakan menjadi $\mathrm{B}_{1}$, K 125, K 175, dan K 225. Pada mutu beton ini pegawasannya hanya dibatasi sampai pada pengawasan mutu material untuk kuat tekan tidak diwajibkan pemeriksaannya.

c. Beton kelas III

Beton kelas tiga yaitu beton yang biasanya diaplikasikan pada pekerjaan struktur yang lebih tinggi dibandingkan beton kelas dua. Dalam pelaksanaan belon kelas dua membutuhkan keahlian tinggi dan dikerjakan berdasarkan pengawasan pimpinan ahli. Pada beton kelas tiga diwajibkan adanya laboratorium beton yang komprehensif dengan alat serta sarana prasarana yang layak dan dilaksanakan oleh orang yang mahir tentang beton yang dapat melaksanakan pengawasan terhadap mutu beton secara berkelanjutan [2].

Tabel 1. Kelas dan Mutu Beton

\begin{tabular}{c|c|c|c|c|c|c}
\hline Kelas & Mutu & $\begin{array}{c}\sigma^{\prime} \mathbf{b k} \\
\left(\mathbf{k g} / \mathbf{c m}^{2}\right)\end{array}$ & $\begin{array}{c}\sigma^{\prime} \mathbf{b m} \\
\left(\mathbf{k g} / \mathbf{c m}^{2}\right)\end{array}$ & Tujuan & \multicolumn{2}{|c}{$\begin{array}{c}\text { Pengawasan } \\
\text { terhadap mutu } \\
\text { kekuatan agregat } \\
\text { tekan }\end{array}$} \\
\hline $\mathrm{I}$ & $\mathrm{B}_{0}$ & - & - & $\begin{array}{c}\text { Non } \\
\text { Struktural }\end{array}$ & Ringan & Tanpa \\
\hline
\end{tabular}




\begin{tabular}{c|c|c|c|c|c|c}
\hline \multirow{4}{*}{ II } & $\mathrm{B}_{1}$ & - & - & Struktural & Sedang & Tanpa \\
\cline { 2 - 7 } & $\mathrm{K} 125$ & 125 & 200 & Struktural & Ketat & Kontinyu \\
\cline { 2 - 7 } & $\mathrm{K} 175$ & 175 & 250 & Struktural & Ketat & Kontinyu \\
\cline { 2 - 7 } & $\mathrm{K} 225$ & 225 & 200 & Struktural & Ketat & Kontinyu \\
\hline III & $\mathrm{K}>225$ & $>225$ & $>300$ & Struktural & Ketat & Kontinyu \\
\hline
\end{tabular}

Sumber: Mulyono. T, 2003

2. Berdasarkan Jenis

a. Beton ringan

Beton ringan adalah jenis beton yang memiliki berat lebih ringan dibandingkan beton lainnya. Campuran agregat yang digunakan dalam pembuatan beton ringan adalah agregat ringan. Berat jenis agregat ringan sekita $1900 \mathrm{~kg} / \mathrm{m}^{3}$ dengan kuat tekan pada umur 28 hari > 17,2 MPa.

b. Beton normal

Beton normal merupakan beton yang difabrikasi dengan memanfaatkan material seperti biasa yaitu menggunakan pasir dan split. Specific gravity beton jenis ini sekitar 2200 $\mathrm{kg} / \mathrm{m}^{3}-2400 \mathrm{~kg} / \mathrm{m}^{3}$. Sedangkan kuat tekan beton jenis ini bekisar $15-40 \mathrm{MPa}$.

c. Beton berat

Beton berat ialah beton yang difabrikasi dengan material yang mempunyai berat lebih tinggi daripada beton normal. Untuk mencapai beton berat maka digunakan juga agregat dengan specific grafity yang tinggi.

d. Beton massa

Beton massa merupakan beton yang dimanfaatkan dalam pekerjaan yang scopenya besar dan massif. Beton massa biasanya digunakan pada konstruksi jembatan, bendungan, jembatan dan lain-lain.

e. Beton serat

Beton serat yaitu beton yang campurannya ditambah dengan fibre. Fibre pada beton digunakan sebagai pencegah retakan oleh karena itu, beton lebih daktail dibandingkan beton normal.

\section{Pelat Lantai}

Pelat lantai adalah elemen struktur bangunan yang memiliki ketebalan yang sangat tipis daripada elemen struktur lainnya yang diberikan tulangan besi kemudian dicor beton sesuai dengan beban yang akan didukungnya.

Pelat lantai termasuk struktur rigid yang terbuat dari material beton bertulang yang ketebalannya lebih kecil daripada dimensi elemen struktur lainnya (Lim, 2018). Pada umumnya, pelat lantai mendukung beban-beban yang bersifat menyebar ke segala 
arah. Pelat lantai diklasifikasikan menjadi beberapa macam seperti pelat tebal, pelat tipis dengan defleksi besar, dan pelat tipis dengan defleksi kecil. Pelat tipis adalah pelat berdasarkan perbandingan thickness dan panjangnya paling pendek kurang dari 1/20. Sedangkan yang dimaksud dengan pelat lantai dengan defleksi kecil merupakan pelat lantai jika defleksinya kurang dari thickness pelat tersebut.

\section{Metode Hirzfeld}

1. Pelat Yang Ditumpu Sederhana

Metode hirzfeld merupakan metode yang digunakan untuk menyelesaikan pelat menggunakan pendekatan teori balok yang dikembangkan oleh seseorang berkebangsaan Jerman. Metode ini biasa digunakan momen lentur pelat dengan kondisi tepi yang particular pada dua sisi yang berlawanan yaitu $\mathrm{x}=0$ dan $\mathrm{x}=\mathrm{a}$. Dan sembarang kondisi tumpuan tepinya pada $\mathrm{x}= \pm \frac{\mathrm{b}}{2}$. Total persamaan lendutan dapat diselesaikan dengan rumus berikut:

$$
\frac{d^{2} f}{d x^{2}}=\frac{M_{x}}{E I}
$$

Maka, nilai momen pada perletakan sendi di atas dengan jarak sejauh $x$ yaitu:

$$
\begin{aligned}
& M_{x}=R_{A} \cdot x-\frac{1}{2} q \cdot x^{2} \\
& \frac{d^{2} f}{d x^{2}}=\frac{R_{A} \cdot x-\frac{1}{2} q \cdot x^{2}}{E I}
\end{aligned}
$$

Dengan reaksi perletakan sebagai berikut:

$$
\mathrm{R}_{\mathrm{A}}=\frac{1}{2} \mathrm{ql} \text { dan } \mathrm{R}_{\mathrm{B}}=\frac{1}{2} \mathrm{ql}
$$

Setelah diketahui rumus diatas maka, momen lentur dapat dihitung menggunakan rumus sebagai berikut:

$$
\mathrm{M}_{\mathrm{x}}=\frac{\mathrm{q}_{\mathrm{x}} \cdot \mathrm{l}_{\mathrm{x}}^{2}}{8} \text { dan } \mathrm{M}_{\mathrm{y}}=\frac{\mathrm{q}_{\mathrm{y}} \cdot \mathrm{l}_{\mathrm{y}}^{2}}{8}
$$

2. Pelat Dengan Kedua Tepinya Berhadapan Yang Ditumpu Sederhana dan Kedua Sisi Lainnya Terjepit

Kemudian untuk masalah ini, jika pelat ditinjau dari arah x maka dapat digunakan persamaan lendutan arah $\mathrm{x}$ sebagai berikut:

$$
\mathrm{f}_{\mathrm{x}}=\frac{5}{384} \frac{q_{x} \mathrm{l}_{\mathrm{x}}^{4}}{\mathrm{D}_{\mathrm{x}}}
$$

Maka, momen lentur pada kondisi ini dapat dihitung dengan rumus sebagai berikut: 


$$
\mathrm{M}_{\mathrm{x}}=\frac{\mathrm{q}_{\mathrm{x}} \cdot \mathrm{l}_{\mathrm{x}}^{2}}{8} \text { dan } \mathrm{M}_{\mathrm{y}}=\frac{\mathrm{q}_{\mathrm{y}} \cdot \mathrm{l}_{\mathrm{y}}^{2}}{24}
$$

3. Pelat Dengan Ketiga Tepinya Ditumpu Sederhana dan Satu Sisi Lainnya Terjepit

Kemudian untuk masalah ketiga, apabila pelat ditinjau dari arah x maka dapat digunakan persamaan sebagai berikut:

$$
\mathrm{f}_{\mathrm{x}}=\frac{5}{384} \frac{\mathrm{q}_{\mathrm{x}} \mathrm{l}_{\mathrm{x}}^{4}}{\mathrm{D}_{\mathrm{x}}}
$$

Maka, momen lentur yang terjadi pada kondisi ini adalah sebagai berikut:

$$
\mathrm{M}_{\mathrm{x}}=\frac{\mathrm{q}_{\mathrm{x}} \cdot \mathrm{l}_{\mathrm{x}}^{2}}{8} \text { dan } \mathrm{M}_{\mathrm{y}}=\frac{9 \mathrm{q}_{\mathrm{y}} \cdot \mathrm{l}_{\mathrm{y}}^{2}}{128}
$$

4. Pelat Yang Semua Tepinya Terjepit

Pada kondisi ini, persamaan defleksi dapat ditinjau dari dua arah yaitu $\mathrm{X}$ dan $\mathrm{Y}$, dimana $\mathrm{X}$ dan $\mathrm{Y}$ adalah tumpuan jepit-jepit mka $\mathrm{fx}=\mathrm{fy}$

$$
f_{x}=\frac{q_{x} l_{x}^{4}}{384 D_{x}} \operatorname{dan} f_{y}=\frac{q_{y} l_{y}^{4}}{384 D_{y}}
$$

Momen lentur pada kondisi ini dapat dihitung menggunakan rumus sebagai berikut:

$$
\mathrm{M}_{\mathrm{x}}=\frac{\mathrm{q}_{\mathrm{x}} \cdot \mathrm{l}_{\mathrm{x}}^{2}}{24} \operatorname{dan} \mathrm{M}_{\mathrm{y}}=\frac{\mathrm{q}_{\mathrm{y}} \cdot \mathrm{l}_{\mathrm{y}}^{2}}{24}
$$

\section{METODE}

Pada penelitian studi kasus yang digunakan adalah proyek pembangunan rumah mewah di Bukit Permata Kota Batam. Pada penelitan ini juga akan digunakan metode hirzfeld, yaitu merupakan salah satu metode untuk mengetahui momen lentur yang terjadi pada pelat lantai. Pada kasus ini digunakan dua pelat lantai dengan dimensi berbeda dan kondisi perletakan yang berbeda pula 


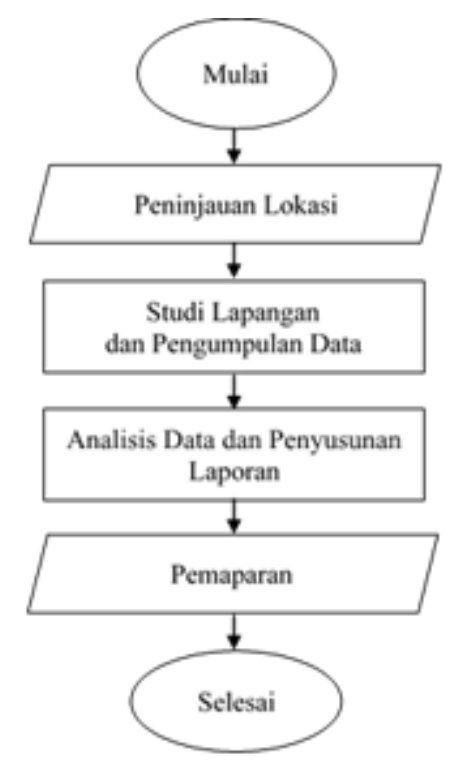

Gambar 1. Bagan Alir Penelitian

\section{HASIL DAN PEMBAHASAN}

1. Pelat Yang Ditumpu Sederhana

Total persamaan lendutan dan kelengkungan balok dapat diselesaikan dengan rumus berikut:

$$
\frac{\mathrm{d}^{2} \mathrm{y}}{\mathrm{dx}^{2}}=\frac{\mathrm{M}_{\mathrm{X}}}{\mathrm{EI}}
$$

Maka momen lentur yang terjadi adalah sebagai berikut:

$$
\begin{gathered}
M_{x}=\frac{\mathrm{q}_{\mathrm{x}} \mathrm{L}_{\mathrm{x}}^{2}}{8}=\mathrm{k} \cdot \frac{\mathrm{q}_{\mathrm{x}} \mathrm{L}_{\mathrm{x}}^{2}}{8} \\
\mathrm{M}_{\mathrm{y}}=\frac{\mathrm{q}_{\mathrm{y}} \mathrm{L}_{\mathrm{x}}^{2}}{8}=(1-\mathrm{k}) \cdot \frac{\mathrm{qL}_{\mathrm{y}}^{2}}{8}
\end{gathered}
$$

\begin{tabular}{|c|c|c|c|c|c|c|}
\hline \multirow{2}{*}{$\begin{array}{c}\text { No } \\
\text { Penampang }\end{array}$} & \multirow{2}{*}{$\varepsilon=\frac{I_{y}}{I_{x}}$} & \multicolumn{2}{|c|}{ Faktor Beban } & \multirow{2}{*}{$\begin{array}{c}\text { Koefisien } \\
\text { Defleksi } \\
(\alpha)\end{array}$} & \multicolumn{2}{|c|}{ Koefisien Momen Lapangan } \\
\hline & & $\mathbf{k}$ & $(1-k)$ & & $\frac{k}{8}$ & $\frac{1-k}{8}$ \\
\hline 1 & 1,22 & 0,68999 & 0,31001 & 0,0090 & 0,0862 & 0,0388 \\
\hline 2 & 1,45 & 0,81552 & 0,18448 & 0,0106 & 0,1019 & 0,0231 \\
\hline
\end{tabular}

Tabel 2. Koefisien Defleksi dan Momen Lapangan

Tabel 3. Momen Lentur 


\begin{tabular}{|c|c|c|c|}
\hline $\begin{array}{c}\text { No } \\
\text { Penampang }\end{array}$ & $\boldsymbol{\varepsilon}=\frac{\mathbf{I}_{\mathbf{y}}}{\mathbf{I}_{\mathbf{x}}}$ & $\mathbf{M}_{\mathbf{x}}=\mathbf{k} \mathbf{Q} \mathbf{L}_{\mathbf{x}}^{2}$ & $\mathbf{M}_{\mathbf{y}}=(\mathbf{1}-\mathbf{k}) \mathbf{Q} \mathbf{L}_{\mathbf{y}}^{2}$ \\
\hline 1 & 1,22 & 0,08625 & 0,03875 \\
\hline 2 & 1,45 & 0,10194 & 0,02306 \\
\hline
\end{tabular}

2. Pelat Dengan Kedua Tepinya Berhadapan Yang Ditumpu Sederhana dan Kedua Sisi Lainnya Terjepit

Kemudian untuk masalah ini, jika pelat ditinjau dari arah $\mathrm{x}$ maka dapat digunakan persamaan lendutan arah $\mathrm{x}$ sebagai berikut:

$$
\mathrm{f}_{\mathrm{x}}=\frac{5}{384} \frac{\mathrm{q}_{\mathrm{x}} \mathrm{l}_{\mathrm{x}}^{4}}{\mathrm{D}_{\mathrm{x}}}
$$

Pada kondisi ini, nilai momen yang terjadi dengan jarak sejauh nilai x maka, didapatkan rumus:

$$
\begin{aligned}
M_{x} & =-M_{A}+R_{A} \cdot x-\frac{1}{2} \cdot q x^{2} \\
\frac{d^{2} y}{d x^{2}} & =\frac{-M_{A}+R_{A} \cdot x-\frac{1}{2} \cdot q x^{2}}{E I}
\end{aligned}
$$

Maka momen lentur yang terjadi adalah sebagai berikut:

\begin{tabular}{|c|c|c|c|c|c|c|}
\hline \multirow[b]{2}{*}{$\begin{array}{c}\text { No } \\
\text { Penampang }\end{array}$} & \multirow[b]{2}{*}{$\varepsilon=\frac{I_{y}}{I_{x}}$} & \multicolumn{2}{|c|}{ Faktor Beban } & \multirow{2}{*}{$\begin{array}{c}\text { Koefisien } \\
\text { Defleksi } \\
(\alpha)\end{array}$} & \multicolumn{2}{|c|}{ Koefisien Momen Lapangan } \\
\hline & & k & (1-k) & & $\frac{k}{8}$ & $\frac{1-k}{24}$ \\
\hline 1 & 1,22 & 0,30803 & 0,69197 & & 0,03850 & 0,08650 \\
\hline 2 & 1,45 & 0,46924 & 0,53076 & 0,00611 & 0,05866 & 0,06634 \\
\hline
\end{tabular}

$$
\begin{gathered}
M_{x}=\frac{q_{x} L_{x}^{2}}{8}=k \cdot \frac{q_{x} L_{x}^{2}}{8} \\
M_{y}=\frac{q_{y} L_{x}^{2}}{24}=(1-k) \cdot \frac{q_{y}^{2}}{24}
\end{gathered}
$$

Tabel 4. Koefisien Defleksi dan Momen Lapangan

Tabel 5. Momen Lentur

\begin{tabular}{|c|c|c|c|}
\hline $\begin{array}{c}\text { No } \\
\text { Penampang }\end{array}$ & $\boldsymbol{\varepsilon}=\frac{\mathbf{I}_{\mathbf{y}}}{\mathbf{I}_{\mathbf{x}}}$ & $\mathbf{M}_{\mathbf{x}}=\mathbf{k} \mathbf{Q} \mathbf{L}_{\mathbf{x}}^{2}$ & $\mathbf{M}_{\mathbf{y}}=(\mathbf{1}-\mathbf{k}) \mathbf{Q} \mathbf{L}_{\mathbf{y}}^{2}$ \\
\hline 1 & 1,22 & 0,03850 & 0,08650 \\
\hline 2 & 1,45 & 0,05866 & 0,06634 \\
\hline
\end{tabular}


3. Pelat Dengan Ketiga Tepinya Ditumpu Sederhana dan Satu Sisi Lainnya Terjepit

Kemudian untuk masalah ini, jika pelat ditinjau dari arah $\mathrm{x}$ maka dapat digunakan persamaan lendutan arah $\mathrm{x}$ sebagai berikut:

$$
f_{x}=\frac{5}{384} \frac{q_{x} l_{x}^{4}}{D_{x}}
$$

Pada kondisi ini, nilai momen yang terjadi dengan jarak sejauh nilai x maka, didapatkan rumus:

$$
\begin{aligned}
& \mathrm{M}_{\mathrm{x}}=-\mathrm{M}_{\mathrm{A}}+\mathrm{R}_{\mathrm{A}} \cdot \mathrm{x}-\frac{\mathrm{qx}^{2}}{2} \\
& \frac{\mathrm{d}^{2} \mathrm{y}}{\mathrm{dx}^{2}}=\frac{-\mathrm{M}_{\mathrm{A}}+\mathrm{R}_{\mathrm{A}} \cdot \mathrm{x}-\frac{\mathrm{qx^{2 }}}{2}}{\mathrm{EI}}
\end{aligned}
$$

Maka momen lentur yang terjadi adalah sebagai berikut:

\begin{tabular}{|c|c|c|c|c|c|c|}
\hline \multirow[b]{2}{*}{$\begin{array}{c}\text { No } \\
\text { Penampang }\end{array}$} & \multirow[b]{2}{*}{$\varepsilon=\frac{I_{y}}{I_{x}}$} & \multicolumn{2}{|c|}{ Faktor Beban } & \multirow[b]{2}{*}{$\begin{array}{c}\text { Koefisien } \\
\text { Defleksi } \\
(\alpha)\end{array}$} & \multicolumn{2}{|c|}{ Koefisien Momen Lapangan } \\
\hline & & $\mathbf{k}$ & (1-k) & & $\frac{k}{8}$ & $\frac{9(1-k)}{128}$ \\
\hline 1 & 1,22 & 0,47098 & 0,52902 & 0,00613 & 0,05887 & 0,02204 \\
\hline 2 & 1,45 & 0,63875 & 0,36125 & 0,00832 & 0,07984 & 0,01505 \\
\hline
\end{tabular}

$$
\begin{gathered}
M_{x}=\frac{q_{x} L_{x}^{2}}{8}=k \cdot \frac{q_{x} L_{x}^{3}}{8} \\
M_{y}=\frac{9 q_{y} L_{x}^{2}}{128}=\frac{9(1-k)}{128} \cdot \mathrm{qL}_{y}^{2}
\end{gathered}
$$

Tabel 7. Koefisien Defleksi dan Momen Lapangan

Tabel 8. Momen Lentur

\begin{tabular}{|c|c|c|c|}
\hline $\begin{array}{c}\text { No } \\
\text { Penampang }\end{array}$ & $\boldsymbol{\varepsilon}=\frac{\mathbf{I}_{\mathbf{y}}}{\mathbf{I}_{\mathbf{x}}}$ & $\mathbf{M}_{\mathbf{x}}=\mathbf{k} \mathbf{Q} \mathbf{L}_{\mathbf{x}}^{2}$ & $\mathbf{M}_{\mathbf{y}}=(\mathbf{1}-\mathbf{k}) \mathbf{Q} \mathbf{L}_{\mathbf{y}}^{2}$ \\
\hline 1 & 1,22 & 0,05887 & 0,02204 \\
\hline 2 & 1,45 & 0,07984 & 0,01505 \\
\hline
\end{tabular}

4. Pelat Yang Semua Tepinya Terjepit

Kemudian untuk masalah terakhir, apabila pelat ditinjau dari arah $\mathrm{x}$ dan $\mathrm{y}$, maka dapat digunakan persamaan sebagai berikut:

$$
f_{x}=\frac{q_{x} l_{x}^{4}}{384 D_{x}} \operatorname{dan} f_{y}=\frac{q_{y} l_{y}^{4}}{384 D_{y}}
$$


Maka momen lentur yang terjadi adalah sebagai berikut:

$$
\begin{aligned}
\mathrm{M}_{\mathrm{x}} & =\frac{\mathrm{q}_{\mathrm{x}} \mathrm{L}_{\mathrm{x}}^{\mathrm{z}}}{24}=\mathrm{k} \cdot \frac{\mathrm{q}_{\mathrm{x}} \mathrm{L}_{\mathrm{x}}^{3}}{24} \\
\mathrm{M}_{\mathrm{y}}=\frac{\mathrm{q}_{\mathrm{y}} \mathrm{L}_{\mathrm{x}}^{2}}{24} & =(1-\mathrm{k}) \frac{\mathrm{qL}_{\mathrm{y}}^{2}}{24} .
\end{aligned}
$$

\begin{tabular}{|c|c|c|c|c|c|c|}
\hline \multirow[b]{2}{*}{$\begin{array}{c}\text { No } \\
\text { Penampang }\end{array}$} & \multirow[b]{2}{*}{$\varepsilon=\frac{\mathbf{I}_{\mathbf{y}}}{\mathbf{I}_{\mathrm{x}}}$} & \multicolumn{2}{|c|}{ Faktor Beban } & \multirow[b]{2}{*}{$\begin{array}{c}\text { Koefisien } \\
\text { Defleksi } \\
(\alpha)\end{array}$} & \multicolumn{2}{|c|}{ Koefisien Momen Lapangan } \\
\hline & & $\mathbf{k}$ & $(1-k)$ & & $\frac{k}{24}$ & $\frac{1-k}{24}$ \\
\hline 1 & 1,22 & 0,68999 & 0,31001 & & 0,02875 & 0,01292 \\
\hline 2 & 1,45 & 0,81552 & 0,18448 & 0,00319 & 0,03398 & 0,00769 \\
\hline
\end{tabular}

Tabel 9. Koefisien Defleksi dan Momen Lapangan

Tabel 10. Momen Lentur

\begin{tabular}{|c|c|c|c|}
\hline $\begin{array}{c}\text { No } \\
\text { Penampang }\end{array}$ & $\boldsymbol{\varepsilon}=\frac{\mathbf{I}_{\mathbf{y}}}{\mathbf{I}_{\mathbf{x}}}$ & $\mathbf{M}_{\mathbf{x}}=\mathbf{k} \mathbf{Q} \mathbf{L}_{\mathbf{x}}^{2}$ & $\mathbf{M}_{\mathbf{y}}=(\mathbf{1}-\mathbf{k}) \mathbf{Q} \mathbf{L}_{\mathbf{y}}^{2}$ \\
\hline 1 & 1,22 & 0,02875 & 0,01292 \\
\hline 2 & 1,45 & 0,03398 & 0,00769 \\
\hline
\end{tabular}

\section{SIMPULAN}

Dari hasil analisis di atas didapatkan kesimpulan sebagai berikut:

1. Semakin luas penampang maka, semakin besar momen lentur yang diperoleh. Besarnya momen lentur yang diperoleh adalah sebagai berikut:

a. Momen lentur penampang I

- Pada kondisi pertama :0,08620

- Pada kondisi kedua : 0,03850

- Pada kondisi ketiga : :0,05887

- Pada Kondisi keempat : 0,02875

b. Momen lentur Penampang II

- Pada kondisi pertama : 0,10190

- Pada kondisi kedua : :0,05866

- Pada kondisi ketiga : :0,07984

- Pada Kondisi keempat :0,03398

2. Semakin luas penampang maka, semakin besar koefisien defleksi yang diperoleh. Besarnya koefisien defleksi yang diperoleh adalah sebagai berikut:

a. Koefisien defleksi penampang I 
- Pada kondisi pertama : 0,00900

- Pada kondisi kedua : :0,00401

- Pada kondisi ketiga : 0,00613

- Pada Kondisi keempat : 0,00377

b. Koefisien defleksi Penampang II

- Pada kondisi pertama : :0,01060

- Pada kondisi kedua : 0,00611

- Pada kondisi ketiga : 0,00832

- Pada Kondisi keempat : 0,00319

\section{UCAPAN TERIMA KASIH}

Ucapan terima kasih kepada Program Sarjana Teknik Sipil Universitas Internasional Batam, Lembaga Penelitian dan Pengabdian Masyarakat Universitas Internasional Batam dan seluruh pelaku konstruksi pada proyek pembangunan rumah mewah Bukit Permata yang telah memberi dukungan terhadap penelitian ini.

\section{DAFTAR PUSTAKA}

Hudori, M. and Wijaya, I. (2019) 'Desain Rancangan Percobaan Pada Pengujian Kuat Tekan Beton Berbahan Campuran Cangkang Kemiri', 3(1), pp. 12-19.

Kusumaningtyas, P. (2014) Laporan Kerja Praktek.

Lim, D. H. (2018) Analisa Plat Lantai Di Proyek Pembangunan Apartemen One Residence Batam Centre. Kota Batam.

Nawy, E. G. (1998) Beton Bertulang Suatu Pendekatan Dasar. Edited by T. Surjaman. PT Refika Aditama.

Sihombing, R. A. (2009) Analisa Pelat Persegi Panjang Dengan Metode Hirzfeld dan Metode M. Levy. Universitas Sumatera Utara.

Tampubolon, F. B. and Tarigan, J. (2002) 'Analisis Perencanaan dan Eksperimental Pelat Lantai Precast Satu Arah Dengan Menggunakan Beton Ringan Untuk Bangunan Ruko dan Tempat Tinggal'. 